\title{
LETTER
}

\section{Time to consider histologic pattern of lung injury to treat critically ill patients with COVID-19 infection}

\author{
Marie-Christine Copin ${ }^{1}$, Erika Parmentier ${ }^{2}$, Thibault Duburcq ${ }^{2}$, Julien Poissy ${ }^{3 *}$, Daniel Mathieu ${ }^{2}$ and The Lille \\ COVID-19 ICU and Anatomopathology Group
}

@ 2020 Springer-Verlag GmbH Germany, part of Springer Nature

Dear Editor,

In their editorial about 'COVID-19 pneumonia: different respiratory treatment for different phenotypes' Gattinoni et al. [1] hypothesize a sequence of events in critically ill patients infected by SARS-CoV-2. They describe a type $\mathrm{L}$ characterized by a low elastance, a low ventilation to perfusion ratio, a low lung weight and a low lung recruitability. Worsening patients are supposed to progress from type $\mathrm{L}$ to type $\mathrm{H}$. Type $\mathrm{H}$ is characterized by a high elastance, a high right-to-left shunt, a high lung weight and a high lung recruitability. As Gattinoni and colleagues complete their editorial, "understanding the correct pathophysiology is crucial to establishing the basis for appropriate treatment".

Postmortem biopsies were performed in Lille University Hospital between 2020 March 6th and April 5th 2020 on six COVID-19 positive patients at different stages of the disease, after family consent. For the first patient, who died early in its disease course after withdrawing of treatment, 5 days after the beginning of fever, we found a lymphocytic viral pneumonia (Fig. 1a) that could be considered as type L. For five other patients, who died later in their disease course, around 20 days after the beginning of symptoms with a phenotype $\mathrm{H}$, the histologic pattern was an acute fibrinous and organizing pneumonia (AFOP), characterized by an extensive intra-alveolar fibrin deposition called fibrin «balls», rather than hyaline

\footnotetext{
*Correspondence: julien_poissy@hotmail.fr

${ }^{3}$ Inserm U1285, CHU Lille, Pôle de réanimation, CNRS, UMR 8576 - UGSF Unité de Glycobiologie Structurale et Fonctionnelle, Univ. Lille, 59000 Lille, France

Full author information is available at the end of the article
}

membranes. Organizing pneumonia consisting of intraluminal loose connective tissue was observed within the alveolar ducts and bronchioles associated with the fibrinous acute injury (Fig. 1b). Fibroblastic bodies and fibroblasts surrounding intra-alveolar fibrin were seen in all cases (Fig. 1c), as well as a moderate interstitial T-cell lymphocytic, a plasma cells infiltrate, and type 2 pneumocyte hyperplasia with cytologic atypia. Vascular injury was also a prominent feature readily, demonstrated by endothelial injury with cytoplasmic vacuolization and cell detachment in small to medium-sized pulmonary arteries (1D).

AFOP, a rare form of acute lung injury, was first described by Beasley et al. [2] and found in SARS-CoV-1 positive cases [3]. This pattern differs from the diffuse alveolar damage (DAD) found in the classic ARDS by the fact that organizing intra-alveolar fibrin constitutes the dominant histologic finding.

From our findings, the fibrin exsudative presence both in alveolar spaces and bronchioles followed by the fibroblastic phase as well as the endothelial injury raise the question of the use of corticosteroids. Indeed, AFOP, especially in its subacute presentation by contrast to the fulminant presentation, is a cortico-sensitive pathology $[2,4,5]$. The AFOP pattern highlights the need for a welldesigned controlled trial, the best schedule of corticotherapy remaining to be determined.

In addition, the obliterative pattern of lung injury in severe cases of SARS-CoV-2 infection raises question about the potential deleterious effect of a ventilation at high PEEP level. Ventilation protocol should be tailored according to patient phenotype in order to avoid additional damage.

\section{Springer}



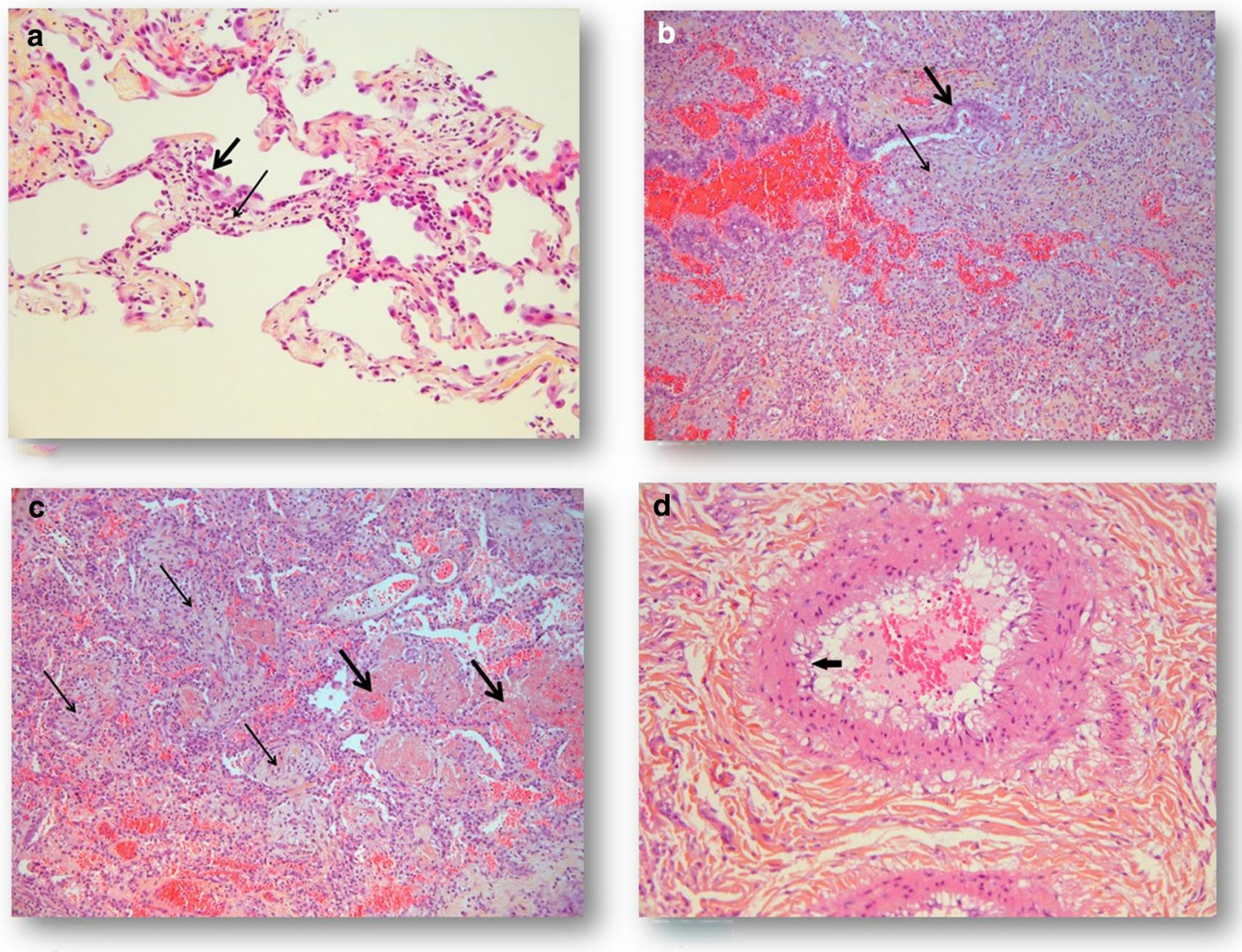

Fig. 1 COVID-19 pulmonary histological findings. a Infiltration of alveolar walls by numerous lymphocytes and edema (thin arrow). Type 2 pneumocyte hyperplasia with cytologic atypia (thick arrow). HES $\times 200$. b Intraluminal loose connective tissue (thin arrow) within bronchiole (bronchiolitis obliterans). Bronchiolar epithelium, thick arrow HES $\times 200$. c Organizing pneumonia (thin arrow) within the alveolar ducts coexisting with fibrin balls (thick arrow). HES $\times 200$. d Endothelial damage: cytoplasmic vacuolization of endothelial cells (arrow). HES $\times 200$

In conclusion, lung injury in severe SARS-CoV-2 infection is not a diffuse alveolar damage. Understanding the pathophysiology of COVID-19 is crucial to apply the appropriate treatment.

\section{Author details}

1 Institut de Pathologie, CHU Lille, Univ. Lille, Avenue Oscar Lambret, 59000 Lille, France. ${ }^{2}$ Pôle de reanimation, CHU Lille, Univ. Lille, Avenue Oscar Lambret, 59000 Lille, France. ${ }^{3}$ Inserm U1285, CHU Lille, Pôle de réanimation, CNRS, UMR 8576 - UGSF - Unité de Glycobiologie Structurale et Fonctionnelle, Univ. Lille, 59000 Lille, France.

\section{Acknowledgements}

Members of the Anatomopathology Group: Morgan Caplan, Nicolas Cousin, Arthur Durand, Julien Goutay, Ahmed El Kalioubie, Raphaël Favory, Patrick Girardie, Marion Houard, Emmanuelle Jaillette, Mercé Jourdain, Geoffrey Ledoux, Anne-Sophie Moreau, Christopher Niles, Saad Nseir, Thierry Onimus, Sébastien Préau, Laurent Robriquet, Anahita Rouzé, Arthur Simonnet, Sophie Six, Aurélia Toussaint - CHU Lille, Pôle de réanimation, F-59000, Lille, France; Romain Dubois, Jean-Baptiste Gibier, Sarah Humez - CHU Lille, Institut de Pathologie, Avenue Oscar Lambret, F-59000 Lille, France.

\section{Author contributions}

MCC, JP and DM wrote the paper. MCC performed the histopathological analysis and analysed the clinical files. EP, TD, JP and DM performed the biopsies and analysed the clinical files.

\section{Compliance with ethical standards}

\section{Conflicts of interest}

All the authors declare no conflict of interest.

\section{Publisher's Note}

Springer Nature remains neutral with regard to jurisdictional claims in published maps and institutional affiliations.

Accepted: 13 April 2020

Published online: 23 April 2020

\section{References}

1. Gattinoni L, Chiumello D, Caironi P, Busana M, Romitti F, Brazzi L, Camporota L (2020) COVID-19 pneumonia: different respiratory treatment for 
different phenotypes? Intensive Care Med. https://doi.org/10.1007/s0013 4-020-06033-2

2. Beasley MB, Franks TJ, Galvin JR, Gochuico B, Travis WD (2002) Acute fibrinous and organizing pneumonia: a histological pattern of lung injury and possible variant of diffuse alveolar damage. Arch Pathol Lab Med 126(9):1064-1070

3. Hwang DM, Chamberlain DW, Poutanen SM, Low DE, Asa SL, Butany J (2005) Pulmonary pathology of severe acute respiratory syndrome in Toronto. Mod Pathol 18(1):1-10
4. Wang Y, Li Y, Wang Q, Zhang L, Li J, Zhu C (2019) Acute fibrinous and organizing pneumonia: a case report. Medicine (Baltimore) 98(8):e14537 5. López-Cuenca S, Morales-García S, Martín-Hita A, Frutos-Vivar F, Fernández-Segoviano P, Esteban A (2012) Severe acute respiratory failure secondary to acute fibrinous and organizing pneumonia requiring mechanical ventilation: a case report and literature review. Respir Care 57(8):1337-1341 